\title{
A Study on the Impact of Tourism Product Placement Marketing on Tourism Intention
}

\section{Wan-Yu Chang}

Department of Tourism and MICE Management, Chung Hua University, Hsinchu City, Taiwan, R.O.C.

\section{Abstract}

With the strong marketing of the global movie industry and the increasing international tourists, a wave of movie sight-seeing agitation has been popularized in the world. Therefore, the study explores the interrelationship between domestic movie tourism's recollection, tourism products attitudes, and tourism Intention, also discusses whether viewers noticed the information of sightseeing products appearing in the movie during the process of watching movies and started to recollect the product with a desire to buy. While in the process of processing the information, the viewer's perception of

Corresponding Author: Wan-Yu Chang wchang@chu.edu.tw

Received: 29 August 2018 Accepted: 18 September 2018 Published: 11 November 2018

Publishing services provided by Knowledge $\mathrm{E}$

(c) Wan-Yu Chang. This article is distributed under the terms of the Creative Commons

Attribution License, which permits unrestricted use and redistribution provided that the original author and source are credited.

Selection and Peer-review under the responsibility of the ICOI-2018 Conference Committee.
G OPEN ACCESS the product will influence the process, the best way for tourism products placed in a movie is combined the vision with auditory. Time and frequency of product exposure will also affect viewers' recollection of products. The purpose of this study was to investigate the effect of placing tourism products into Taiwanese drama to verify the causal relationship. This study takes questionnaire as an experimental tool and takes the participants' recollection of the sightseeing spots in the movie before and after watching for verifying the impact of tourism products using different placement methods and exposure effects on recollection, attitude, and Intention of products, and to explore their tourism intention. The study method is mainly the standard design. And the content includes product recollection and attitude, tourism Intention, and basic personal information. The statistical methods such as variance analysis, correlation analysis, and dependent sample T verification are used for analysis.

Keywords: film-induced tourism, product placement marketing, product recollection, product attitude, tourism intention

\section{Introduction}

Taiwan is known as the llha Formosa. Although with small areas, but it is rich in natural resources and landscapes, such as Taroko gorge, in the east, is famous for its steep marble canyons around the world; southern Ali Mountains are famous for the preservation of numerous towering shenmu; Yushan Mountain, which has an elevation of 3,295 meters, is regarded as the highest peak in Northeast Asia. It can be seen that Taiwan has quite a lot of valuable sightseeing spots worth visiting. In the government's vigorous promotion of marketing techniques to Chinese and foreign tourists, various 
types of advertising marketing campaigns are often used, but the effectiveness of the promotion is rather limited. The main reason is that the products are not properly packaged. Therefore, if we really and truly want to drive the domestic tourism market, it is necessary to implement another marketing method that is different from the past.

There have been many successful examples in recent years. For example, in Taiwan, the wave of the cape in the past led many visitors go to Hengchun, the location where the Cape No. 7 filmed, to experience the charm of the Cape No. 7; and"Monga",a Chinese movie, have recently been taken seriously: the Taipei City Government funded for shooting with vigorous publicity, and also reactivated Wanhua Bopiliao Historical Block. Yi (2003) pointed out that placing sightseeing spots into the theater would increase the audience's interest and curiosity in the attractions in the drama and have the desire to visit the sightseeing and carry out tourism activities. Therefore, it was said that through the influence of the mass media, it is particularly important to promote the local sightseeing spots in the world.

After the implementation of weekend rest by government, the work style of the Chinese people was changed and short-term fixed-point leisure travel activities in the neighboring regions of the country was conducted (Chang, 2009). This study will use Taiwanese drama as a medium, tourist attractions will be placed in the movie and presented in front of the viewers through the plots to explore whether the attraction of sightseeing spots in the movie can induce the viewers' intention to visit the sightseeing and further explore whether the sightseeing spots can be used in the story as a tourism motive for leisure travel.

The results of the study will analyze the effect of placement marketing of movieinduced tourism spots and their impact on potential customers' Tourism intention, and further suggest how the tourism industry can develop tourism through movie-induced tourism, driving local tourist crowds, and generating cultural influence, and can also bring about considerable sightseeing economic benefits.

\section{Literature Review}

\subsection{Movie/film induced tourism}

The concept of movie/film induced tourism was first proposed by Metz in 1982. People agree with the characters in the movie to experience the place where the character has experienced. This implies that a movie can influence the viewers' conception about the tourism destination and the decision-making for their visit. 
Evans (1997) further defined the Movie/Film Induced Tourism. He proposed "movie induced tourism", which included the purpose of screen report by tourists visiting TV, video tapes, or movie theaters. When people choose to travel a certain place or spot because they had been exposed to the media related to the movie or film, this behavior can be called "movie induced tourism" (Hudson \& Ritchie, 2006). Movie induced tourism has become a global trend in recent years. Movie/film media has become a new type of travel guide. When viewers watch movies or television shows, a subtle emotion on the shooting location will be created, which in turn affects their intention to travel the shooting destination. As a result, tourism marketing personnel actively use films, teleplay, and television texts to convey messages in an attempt to produce an effect on viewers and deliberately design attractive travel products.

In response to the wave of movie induced tourism, many related studies have been proposed. In 2006, Hudson and Ritchie divided the contents of relevant literature into four categories:

1. The influence of movie/film on the decision-making of tourist sites

2. The influence of movie/film induced tourists themselves

3. The influence of movie/film-induced tourism on the number of tourists and residents

4. Local marketing activities for movie//film-induced tourism.

After combining movie and sightseeing, it is no longer merely the media but the meaning of carrying more culture and values (Hudson \& Ritchie, 2006; Busby \& Klug, 2001).

\subsection{Product placement marketing}

Product Placement marketing is an advertising noun created by Taiwanese media. Its original source was advertising marketing method "product placement" (Cheng, 2003). Product placement, which originated in the United States, pointed out in its marketing research that placements were mainly placed on teleplay (d'Astous \& Seguin, 1999) or in films (Nebenzahl \& Secunda, 1993; Babin \& Carder, 1996; Gupta \& Lord, 1998). With the development of movie induced marketing so far, the scope of product placement has also gradually expanded. From the traditional product placement to the placement marketing of brand or corporate image, this is undoubtedly more powerful for advertisers and advertising industry, not only can be used as marketing but also to increase the effectiveness of promotion (d'Astous \& Seguin, 1999; Sally \& Jia, 2003). 
The so-called "product placement" is a paid-to-embedded-advertising method, planned and unobtrusive shooting technique that places product messages on teleplay and movies to influence viewers' perceptions on the product (Hong, Wang, \& De Los Santos, 2008); this is a perceptual appeal method with a low degree of involvement, matching the content of the program or the plot direction of the movie for marketing concepts, articles or trademarks, etc., while receiving the product information in the story, reducing the anti-adverse mentality of viewer to advertising. The purpose of "product placement" is to strategically place goods or brands in entertainment media such as teleplay and movies to achieve advertising effectiveness (Balasubramanian, 1994; Lin, 2004).

In 2001, Taiwan Sanlih E-Television Inc. launched the first Taiwanese idol drama titled "Lavender." in Taiwan, the shooting spots in the drama were selected as "Flying Cow Ranch" in the Miaoli area placed into the movie a lot, which caused the viewer's curiosity about this sightseeing spot, and then came to this spot for sightseeing and tourism activities, and the movie made the economic effect of this ranch grow substantially (Yi, 2003). It can be seen that this type of advertising marketing technique that puts products into the movie, also known as "placement marketing", is a good marketing tool for the promotion of the tourism industry in Taiwan. This study will use sightseeing spots with movie to use placement marketing. When viewing a movie, it can also provide information of products (sightseeing spots and related information).

\subsection{Recollection of the tourism product placement}

In the literature discussed recollection of product placement, Gupta, Gould, \& GrabnerKrauter, Russell (2002), and Hsu (2000) all pointed out that in the process of individuals receiving messages, the recollection of products and advertisements is quite equivalent to products. It's important that a good advertising video will make it easier for consumers to remember the products in the advertisement to increase the consumers' impression of the product. Product placement, different placement methods and different exposure effects will also have different effects on viewers' recollection. Therefore, this study explores the products recollection from different placement methods and exposure effects of tourism.

Steortz (1987) believed that product placement should be a combination of auditory and visual tactics, which will result in higher recollection. Steortz (1987) further pointed out that the background of the product is placed must be in the close-up of the lens, and the product or brand is clearly mentioned in the plot. In addition, there are some factors 
that affect product placement, including whether the product is recognized by the character, product exposure time, etc., these factors will affect the consumer's recollection and preferences of the product. D'Astous and Chartier (2000) pointed out that product placement can indeed increase the recollection of the participant, especially when the product is mentioned or presented by the protagonist. In Russell, \& Belch (2005) study, it is pointed out that the placement way of combining visual and auditory is higher than that of visual placement. Liu (2002) mentioned that brand recognition will affect the effectiveness of advertising. When the brand recognition is higher, there will be better advertising results, including product recollection, product attitude and purchase intention. Another factor that influences product recollection is "product exposure effect", the length and frequency of product exposure, that is the Exposure Effect. The socalled exposure effect is the effect that appears when a particular marketing object repeatedly enhances exposure. When objects are repeatedly presented to viewers more times, the more positive the viewer is to the object (Tsai, 2002). Steortz (1987) stated that if $20 \%$ of viewers in a movie have the ability to recall and recognize the same brand, it is an "effective" placement.

Many studies have also shown that the exposure time and the significance of the product placement will affect the viewer's product recollection (Gupta \& Gould, 1997; d'Astous \& (harter, 2000). It can be seen an important issue for marketers. Marketers can arrange for their products to be placed in the movie to take into account the exposure time and the placement method. The products they have promoted can be placed into the movie in the most natural and long-lasting manner to reach the purpose of their marketing promotion. In this study, we mainly discuss interesting spots that have been placed, the placement methods, and the different exposures so that the viewers can leave memories and make a good impression. In the aspect of recollection, this study mainly measured the participants' recollection on attractions in the movie after watching it.

\subsection{Product attitude}

Attitude is a positive or negative overall assessment of a feasible plan. Once a choice is made, it will play a guiding role and will be difficult to change. Therefore, consumers' attitudes toward products will determine whether or not to purchase a product, so changing people's attitudes is a universal marketing goal. Attitude is a kind of psychological process. The evaluation of things produces a continuous tendency. So attitude is an internalization process. When expressed in words or behavior on the outside, 
from some of the signs of behavior, this attitude is inferred (Oskamp \& Kleinke, 1970). Scholar Blackwell Miniard Engel pointed out that attitudes towards a product or brand can strongly influence behavior (Blackwell Miniard Engel, 2001). It can be seen that consumers' attitudes toward products (tourist attractions) are one of the important indicators that determine whether they will purchase this product in the future. Therefore, the purpose of marketing communication is to make consumers have a positive attitude toward products, and make products create a better product image in the minds of consumers.

Attitude cannot directly observe the inner psychological process and must be known through indirect means. In general, attitude scales are mostly developed by social psychologists, while consumer psychologists are used in marketing. Attitude is a state that comes from long-term learning. The individual expresses the status of a particular thing and show their likes or dislikes. Fishbein and Ajzen, 2010 pointed out that attitude was the consumer's preference for a certain goal. If consumers themselves have a good attitude towards a certain product, and there is a demand for this product, it will generate a purchase intention.

\subsection{Tourism intention}

"Intention" can be defined as the individual's inclination to anticipate and plan for the future behavior, and intention can be the best predictor of human future behavior (Swan, 1981; Fishbein \& Ajzen, 1975; Lam \& Hsu, 2006). In the 1980s, Ragheb first brought the intention into tourism-related research and defined the intention to travel as the frequency of individual participation in tourism activities. Folkes (1988) defined the intention as the tendency of a person to subjectively judge his future actions. Some scholars like Chen (2013) believed that the intention represents the degree of personal involvement in leisure activities and the degree of intention to participate in leisure activities. Lee, Chen, and Che (2010) defined the intention to travel as the possibility of purchasing the tourism product, which is a concept of readiness-to-buy. The domestic scholar Chen (2004) also defined the intention to travel as the possibility of tourists wishing to travel to a tourist destination. Respondents in this study have increased or decreased their interest in products (tourist attractions) after viewing the movie, which indirectly influences the intention of future respondents to travel on products. 


\section{Research Methods}

The study was conducted in the form of experimental movies and questionnaires. The main purpose of the study was to detect whether the participants watched the sightseeing spots in the movie and whether they would be willing to travel to the destination after viewing and explaining experimental movie, the impact of the preview concept as research data. Therefore, the study only focuses on participants' recollection, attitude, and intention to the sightseeing spots placed on the movie for designing and exploring the participants' acceptability of the sightseeing spots. The movie chosen in this study was "A Boy Named Flora A". The main cities of this movie were Taichung Wuri and Dadu Ruijing Community. The simple rural community had common three-section compound, brick wall and corners, and surrounding unique human landscape and ecological resources of Dadu Mountain, such as the migration of the purple butterfly.

This study mainly discusses whether the viewers noticed the information that appeared in the movie during watching it and began to recollection the products and the intention to visit. According to the previous literature review and research purposes, research framework and research hypothesis were proposed in this paper.

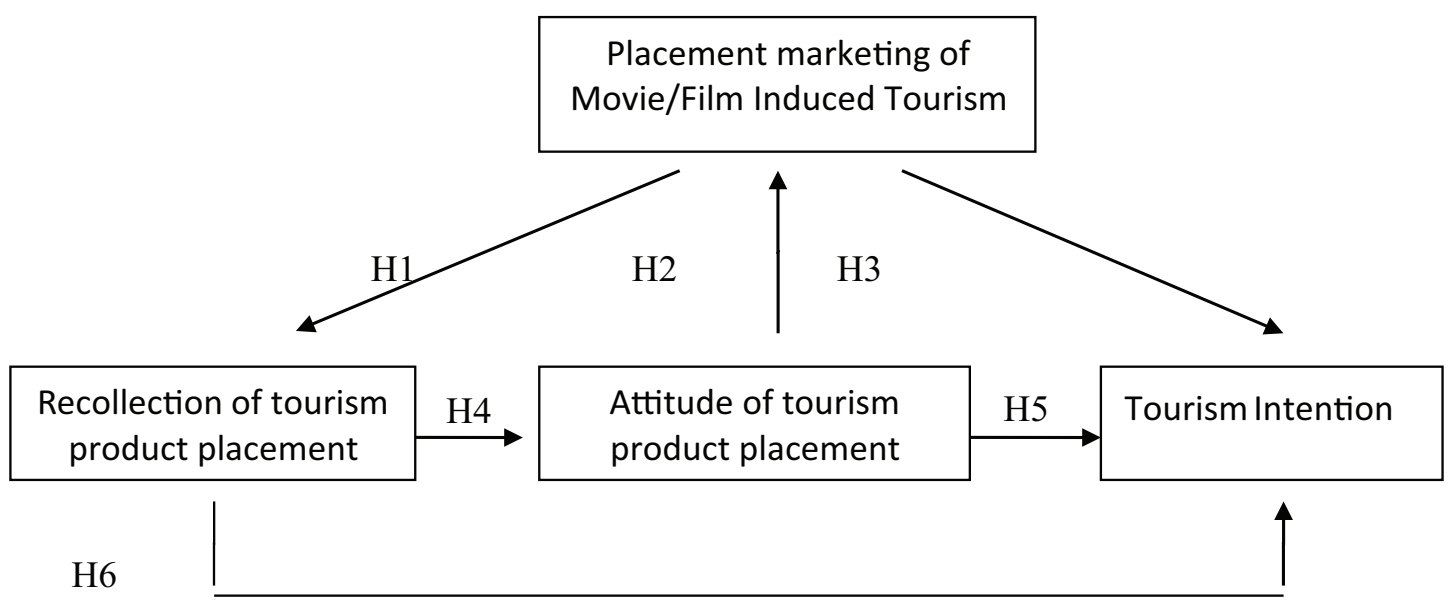

Figure 1: Research Framework.

\subsection{Research hypothesis}

$H$ 1: There is a significant effect on the recollection of the attractions after watching movie. 
$\mathrm{H}$ 2: There is a significant effect on the attitude of the attractions after watching movie.

H 3: There is a significant impact on the intention to travel after watching movie.

$\mathrm{H}$ 4: There is a correlation between the recollection and the attitude of the attraction.

$\mathrm{H}$ 5: There is a correlation between the attitude of the attractions and the intention to travel.

H 6: There is a correlation between the degree of recollection and the intention to travel.

\section{Questionnaire Design}

This study mainly examines whether the viewers noticed the sightseeing spots that appeared in the movie and whether they would like to travel it. The study uses different placement methods and exposure effects of sightseeing spots to detect the resulting advertising. There is no need to use a questionnaire to determine placement method and exposure effect. Therefore, the questionnaire is designed and explored only for the participants' recollection, attitude, and intention to sightseeing spots in the movie and their attitude to product placement marketing. The process of watching experiment movies and questionnaires will be used to conduct the experiment. The study allows the participants to fill out the questionnaire before and after watching the movie. After completing the questionnaire before watching, the participants are allowed to watch the edited 5-minute experiment movie "A Boy Named Flora $A^{\prime \prime}$, and then completing questionnaires that is divided into pre-test and post-test questionnaires, mainly to measure the difference between the study sample before and after watching the experimental movie. The pre-test questionnaire and post-test questionnaire must be filled in by the same person. This study expects to issue 240 pre-view and post-view questionnaires.

The questionnaire includes pre-test and post-test questionnaires. The content of the questionnaire is as the following:

\subsection{Pre-test questionnaire}

1. Screening Sample: Participants who have watched $70 \%$ or more of the movie and who watched the $30 \%$ or more of the experiment movie are filtered out of the study. 
2. The recollection of placement product: After watched the Taiwanese drama set by the television media, the participants' recollection of the sightseeing spots appeared in the drama will be discreetly selected as the actual test sample that met the study. If most of the participants could not answer correctly, indicating that their frequency of watching Taiwanese drama was very low. Therefore, such samples could be listed as the post-measurement objects of this study and the nominal scale should be adopted.

3. The Attitude of Placement Product: The contents of the questionnaire were mainly used to test participants' attitudes towards placement marketing products in Taiwanese drama.

4. Tourism intention: Questions about the Tourism intention to Taichung attraction spots.

\subsection{Post-test questionnaire}

After the eligible samples were screened through the first phase of the pre-test questionnaire, the eligible participants would be allowed to fill in the post-test questionnaire. The post-test questionnaire mainly tested the movie content after watching. Its various parts are described as follows:

1. Basic data of the sample: Investigated the participants' gender, age, marital status, place of residence, education, occupation, disposable income per month, leisure entertainment, television viewing trends (movie, American album, Korean play, Japanese play, Taiwanese drama, variety show, news, Talk Shows) watching frequency of each week, with whom, and using what kind of media to watch a play.

2. Product recollection: In the unprompted state, the participants' recollection of the sightseeing spots and plots appearing in the movie, the nominal scale was adopted.

3. Product attitude: This section is mainly discuss the participants' attitude to the main tourist attractions in this experiment, such as Star Township, Zheng Jiazuo, Rui'an Palace, forget worry Valley Flower Sea, Donghai Art Street, Jingyi University, cafes, etc. in the movie after they watching the movie.

4. Tourism intention: After the stimulation of the experimental movie, the intention of the participants to the sightseeing spots in the movie was tested. 


\section{Data Analysis}

This study mainly analyzes the participants' effect on the placement of tourism products. Therefore, this section mainly focuses on the operational verification of the variables in the study, the measurement of the adversary's effects on advertising, and the relevant analysis and explanation. This study uses the Windows for SPSS 22.0 software package as an analysis tool to manipulate verification and perform hypothesis verification. The contents are as follows:

\subsection{Descriptive statistics}

Describe the number of samples in the experimental group and the control group for their placement effects, such as maximum, minimum, sum, average, and standard deviation.

\subsection{Correlation analysis}

This study investigates whether the independent variable has a significant effect on the dependent variable and explores the correlation between product recollection, product attitude, and Tourism intention. The correlation analysis of this study mainly used the Spearman rank of order correlation coefficient to detect the correlation between product recollection, product attitude and Tourism intention. Its description is as follows:

1. Product recollection and product attitude

The correlation analysis was used to explore the correlation between participants' recollection and product attitude.

2. Product recollection and intention to travel

Correlation analysis was used to explore the correlation between the participants' recollection and the intention to travel.

3. Product attitude and intention to travel

The correlation analysis was used to explore the correlation between the subject's attitude toward the product and the intention to travel. 


\subsection{Analysis of variance}

One Way ANOVA is mainly a method to test the average difference of two or more samples at the same time. In this study, the main test is to detect whether there is a significant difference in the effectiveness of different basic data of the participants. The basic information of different individuals detected includes: age, education, place of residence, etc.; placement effects are product recollection, product attitude, and Tourism intention.

\subsection{T-test}

The $T$ test is the hypothesis test of the mean difference, which is mainly used to test the significance of the difference between the two samples. The part to be tested in the $T$ test is divided into an independent sample $T$ test and a dependent sample $T$ test. The independent sample $T$ test is mainly used to test the personal basic data of the participants: age, educational level, and significant test of the effect of the place of residence on a wide range; the dependent sample $T$ test is mainly used to detect product recollection and product placement attitude and post-test significant difference test.

\section{References}

[1] Babin, L.A. \& Carder, S.T. (1995). Advertising via the box office: is product placement effective? Journal of Promotion Management, in press.

[2] Balasubramanian, S. K. (1994). "Beyond advertising and publicity: Hybrid messages and public policy issue". Journal of Advertising, 23(4), 29-46.

[3] Blackwell, D. R., Miniard, P. W. \& Engel, J. F. (2001). Consumer Behavior, 9th ed., Harcourt, Inc.

[4] Busby, G. \& Klug, J. (2001). Movie Induced Tourism: The Challenge of Measurement and Other issues. Journal of Vocation Marketing, 7(4): 316-332.

[5] Chang, Yu-Ying. (2009). A Study on the Influence of Movie-induced Tourism for Tourism Development- "A City of Sadness" And "Cap No.7" As Examples. Master's thesis. Department of Tourism, Shih-Hsin University.

[6] Chen, Hui-Min, 2013. The influence of micro film on destination image and travel intention-The case of "Heartbeat love" to Australia tourism. Master's thesis. Department of Tourism, Shih-Hsin University. 
[7] Chen, Yun-Chin. (2004). The perceptions of destination image and visitor's intention to travel. Master's thesis. Department of Tourism, Ming Chuan University, Taiwan.

[8] Cheng, Tzu-Lung. (2003). Media topic - Embedded marketing is not a viper beast. Brain News, Vol. 324, P70-71.

[9] d'Astous, A., \& Chartier, F. (2000). A study of factors affecting consumer evaluations and memory of product placements in movies. Journal of Current Issues and Research in Advertising, 22(2), 31-40.

[10] d'Astous, A., \& Seguin, N. (1999). Consumer reactions to product placement strategies in television sponsorship. European Journal of Marketing, 33(9), 896-910.

[11] Evans, M. (1997). Plugging into TV tourism, March D35-D38, London: English Tourist Board.

[12] Fishbein, M., \& Ajzen, I. (1975). Belief, attitude, intention, and behavior: An introduction to theory and research. Reading, MA: Addison-Wesley.

[13] Fishbein, M., \& Ajzen, I. (2010). Predicting and changing behavior: The reasoned action approach. New York: Psychology Press.

[14] Folkes, V. S. 1988. Recent Attribution Research in Consumer Behavior: A Review and New Directions. Journal of Consumer Research, 14, 548-565.

[15] Gupta, P. B., \& Gould, S. J. (1997). Consumers' perceptions of the ethics and acceptability of product placements in movies: Product category and individual differences. Journal of Current Issues \& Research in Advertising, 19(1), 37-50.

[16] Gupta, P. B., \& Lord, K. R. (1998). "Product placement in movies: The effect of prominence and mode on audience recall". Journal of Current Issues and Research in Advertising, 20(1), 47-59.

[17] Gupta, P. B., Gould, S. J., \& Grabner-Krauter, S. (2000). Product placements in movies: a cross-cultural analysis of Austrian, French and American consumers' attitudes toward this emerging, international promotional medium. International Journal of Advertising, 29, 41-58.

[18] Hong, S., Wang, Y. J., \& De Los Santos, G. (2008). The effective product placement: Finding appropriate methods and context for higher brand salience. Journal of Promotion Management, 14, 103-120.

[19] Hsu, Mei-Hui. (2000). The Advertising Effect Research of Product Placement in Films. Unpublished Master's Thesis. Department of Journalism, Chinese Culture University, Taiwan.

[20] Hudson, S. and Ritchie, J.R.B. (2006). Promoting destinations via film tourism: an empirical identification of supporting marketing initiatives, Journal of Travel Research, 44(3), pp. 387-396. 
[21] Lam, T., and Hsu, C.H.C. (2006). Predicting Behavioral Intention of Choosing a Travel Destination. Tourism Management, 27 (2), 589-99.

[22] Lee, Ching-Sung, Chen, Sheng-Lin, Che, Cheng-Wei. (2010). The Influences of Media Marketing on Tourist Image, Activity Attraction and Willingness of Visit in Youth Tourism-a Case Study of Matsu Area. Leisure Industry Research, 8(3), 25-43.

[23] Lin, Chung-Chen. (2004). The Effect Research of Product Placement-The Case of Destination in Taiwanese Trendy Drama. Master's thesis. Department of Tourism, Ming Chuan University, Taiwan.

[24] Liu, Mei-Ling. (2002). Research on Subliminal Advertising-Take Product Placement for Example. Master's thesis. Department of Business Administration, National Cheng Kung University.

[25] Nebenzahl, I.D. \& Secunda, E. (1993) Consumers' attitudes toward product placement in movies. International Journal of Advertising, 12, 1-11.

[26] Oskamp, S., \& Kleinke, C. (1970). Amount of reward as a variable in the Prisoner's Dilemma game. Journal of Personality and Social Psychology, 16(1), 133-140.

[27] Ragheb, M. G. (1980). Interrelationships among leisure participation, leisure satisfaction and leisure attitudes. Journal of Leisure Research, 12, 138-149.

[28] Russell, A. C. (2002). Investigating the effectiveness of product placements in television shows: The role of modality and plot connection congruence on brand memory and attitude. Journal of Consumer Research, 29(3), 306-318.

[29] Russell, C. A., \& Belch, M. (2005). A managerial investigation into the product placement industry. Journal of Advertising Research, 45(1), 73-92.

[30] Sally, A.M. and Z. Jia. (2003). Product Placement in Movies: A Comparison of Chinese and American Consumers' Attitudes, International Journal of Advertising, 22, 349374 .

[31] Steortz, E. 1987. The cost efficiency and communication effects associated with brand name exposure within motion picture. Unpublished Master's Thesis, West Virginia University, Morgantown, WV.

[32] Swan, J. (1981). Disconfirmation of expectations and satisfaction with a retail service. Journal of Retailing, 57 (3), 49-66.

[33] Tsai, Shumei. (2002). A Study on Impact of Sports Brand Spokespersons" Source Credibility on Consumer's Intention to Purchase. Unpublished Master's Thesis. Graduate Institute of Management, National Taiwan of Science and Technology, Taipei.

[34] Yi, Huo-Tzu. (2003). Idol dramas drives new tourism attractions in Taiwan. Liberty times, p25. 